\title{
COMMISSION No. 36 \\ THEORY OF STELLAR ATMOSPHERES \\ (THEORIE DES ATMOSPHERES STELLAIRES)
}

President: David F. Gray

Vice President: Wolfgang Kalkofen

\section{New Officers}

It has become the practice of the commission for the president, with the assistance of his organizing committee, to assemble names for the new organizing committee from suggestions of the commission members. It is the president's responsibility to see that a reasonable balance is maintained in geographical distribution and areas of research expertise. Normally the vice president ascends to the presidency. Continuous membership on the organizing committee is limited to two consecutive terms except for the president and vice president. To make this procedure function, We depend on suggestions from the membership for new members of the organizing committee.

The new organizing committee for 1991-94 consists of W. Kalkofen, USA (president); L. Cram, Australia (vice president); Y. Cuny, France; D. Dravins, Sweden; J.L. Linsky, USA; R. Pallavicini, Italy; A. Peraiah, India; A. Sapar, USSR; T. Tsuji, Japan; R. Wehrse, Germany; L.A. Willson, USA (new); and C. Zwaan, Netherlands (new).

Thirty new members joined our commission at this General Assembly: Baade, D., Baliunas, S., Balona, L.A., Basri, G., Bopp, B.W., Catalano, F., Catalano, S., Cuntz, M., Doazan, V., Fontaine, G., Giampapa, M.S., Gigas, D., Glebocki, R., Hall, D.S., Judge, P., Kondo, Y., Lamers, H.J.G.L.M., Luck, R.E., Luttermoser, D.G., Mathys, G., Piskunov, N.E., Rodono, M., Rucinski, S., Ryabchikova, T.A., Schrijver, C.J., Tuominen, I., Walter, F., Vaughan, A.H., Vilhu, O., Wolff, S.C. The commission membership now stands at 266.

\section{Working Groups}

Commission 36 has continued to sponsor the following working groups: Ap/CP Stars, Astrochemistry, Atomic and Molecular Data, Be Stars, Peculiar Red Giants, and Synthetic Photometry.

\section{Meetings Associated with Commission 36}

The following meetings were sponsored or otherwise associated with our commission. Not all were successful in gaining IAU status. Some are yet to be held.

1992 July, "New Perspectives on Stellar Pulsation and Pulsating Variable Stars",

Victoria, D. Welch, J. Nemec.

1992 July, "Planetary Nebulae", Innsbruck, A. Acker.

1992 July, "Peculiar versus Normal Phenomena in A-Type \& Related Stars", Trieste,

M. Hack.

1992 March, "Stellar Chromospheres", Cambridge, U.K., C.S. Jeffery.

1992 February, "Infrared Solar Physics", Tucson D. Deming, D. Rabin.

1992 February, The Tenth Colloquium on "Ultraviolet and X-Ray Spectroscopy of

Astrophysical and Laboratory Plasmas", Berkeley, S.M. Kahn.

1992 January, "Non-Linear Phenomena in Stellar Variability", Mito, M. Takeuti. 
1991 August, "The Astrochemistry of Cosmic Phenomena", Campos de Jordao, A. Dalgarno.

1991 August, "Evolutionary Processes in Interacting Binary Stars", Cordoba, Y. Kondo.

1991 July-August, "Eruptive Solar Flares", Buenos Aires, B.V. Jackson.

1991 July-August, "Solar and Stellar Coronae", Buenos Aires, R. Pallavicini.

1991 July-August, "Chromospheres and Circumstellar Envelopes of Red Giant Stars", Buenos Aires, H.R. Johnson.

1991 July-August, "Astrophysical Opacities", Buenos Aires, S. Sahal-Brechot.

1990 September, "Stellar Atmospheres: Beyond Classical Models", Trieste, "L. Crivellari.

1990 September, "Rotation and Angular Momentum of Low-Mass Stars", Noto, S. Catalano.

1990 August, "Evolution of Stars: the Photospheric Abundance Connection", Druzbe, G. Michaud.

1990 July, "The Sun and Cool Stars: Activity, Magnetism, Dynamos", Helsinki, I.

Tuominen.

1990 July," Surface Inhomogeneities in Late-Type Stars", Armagh, J.G. Doyle.

1990 June, "Mechanisms of Chromospheric and Coronal Heating", Heidelberg, P.

Ulmschneider.

1990 June, "Wolf-Rayet Stars and Interrelations with other Massive Stars in

Galaxies", Denpasar, K.A. van der Hucht.

1990 May, "Confrontation Between Stellar Pulsation and Evolution", Bologna, C.

Cacciari.

1989 December, "Basic Plasma Processes in the Sun", Bangalore, V. Krishan.

1989 October, "Angular Momentum and Mass Loss for Hot stars", Ames, L.A.

Willson.

\section{Meetings held at the General Assembly}

Two scientific sessions were held by Commission 36 during the General Assembly in Bueons Aires. The papers presented are as follows.

\section{Session 1 Extended Atmospheres (Chairman, D.F. Gray)}

S.V. Mallik, "The $\mathbf{H}_{\alpha}$ Line as a Diagnostic of Cool Supergiant Chromospheres."

W.H. Wehlau, "Surface Features on Ap Stars."

J.C. Pecker, "Comments on Non-Sphericity."

A. Peraiah, "Departures from Sphericity in Stellar Atmospheres."

R. Wehrse, "The Solution of the 3D Radiative Transfer Equation."

Session 2 Red Giant Stars (Chairman, H.R. Johnson)

K.G. Carpenter, "Ultraviolet and Visual Observations of Chromospheres."

P. Ulmschneider, "Mechanisms for Heating the Chromosphere."

W. Van der Veen, "Observations of CS Gas and Dust."

A.G. Hearn, "Mechanisms of Mass Loss."

Commission 36 also co-sponsored the Joint Discussion on Solar \& Stellar Coronae (with Commissions 10,12 , and 44). 